\title{
Effect of Pulsed Current Frequency and Anodisation Time on Surface Properties of Electropolished and Nonelectropolished Titanium Substrates
}

\author{
Victória da Costa Marba, ${ }^{1}$ Natal N. Regone, ${ }^{2}$ \\ Eduardo N. Codaro $\mathbb{D}^{1}{ }^{1}$ and Heloisa A. Acciari $\mathbb{D}^{1}$ \\ ${ }^{1}$ Physics and Chemistry Department, School of Engineering, São Paulo State University, Guaratinguetá Campus, \\ 333 Dr. Ariberto Pereira da Cunha Ave., 12516-410 Guaratinguetá, SP, Brazil \\ ${ }^{2}$ São Paulo State University, São João da Boa Vista Experimental Campus, 505 Prof. Isette Corrêa Fontão Ave., \\ 13876-750 São João da Boa Vista, SP, Brazil
}

Correspondence should be addressed to Heloisa A. Acciari; heloisa@feg.unesp.br

Received 8 January 2018; Revised 13 March 2018; Accepted 1 April 2018; Published 6 May 2018

Academic Editor: Ramazan Solmaz

Copyright (C) 2018 Victória da Costa Marba et al. This is an open access article distributed under the Creative Commons Attribution License, which permits unrestricted use, distribution, and reproduction in any medium, provided the original work is properly cited.

Surface characteristics of anodic films formed on electropolished and nonelectropolished titanium substrates have been evaluated using different sets of anodisation parameters at room temperature. Surfaces were analysed by light microscopy, Raman spectroscopy, scanning electron microscopy, and X-ray diffraction. The formation of $\mathrm{TiO}_{2}$ anatase phase was only detected on nonelectropolished substrates and there seems to be a larger amount of anatase as samples are anodised; consequently, the smallest crystals were obtained at the highest frequency of pulsed current. EIS results showed that there is no difference in the degree of compactness along the layer thickness.

\section{Introduction}

Titanium and its alloys have been widely used in biomedical devices, such as dental and orthopaedic implants. In order to improve the osseointegration process of orthopaedic implants, various chemical and topographic modifications have been suggested recently. Several authors have observed that surface modifications using methods such as polishing, electropolishing, etching, anodisation, and plasma electrolytic oxidation are able to improve the speed and quality of osseointegration processes, thus increasing bone deposition and shortening repair period [1-6].

Some modifications reveal nanostructured features that can enhance the growth and attachment of mesenchymal cells and osteoblasts due to increased bioactive area [7, 8]. Many methods have been used to improve interfacial properties and lifetime of implants. Moreover, anodisation at high voltages is rather interesting due to being a simple and replicable process that can influence the chemical composition, morphology, and thickness of anodic films. It can transform an amorphous oxide film into a crystalline oxide; thus the implant surface becomes nanostructured, thereby favouring osteoblastic cell growth and resulting in a more effective osseointegration process $[8,9]$.

According to Yao et al. [10], nanostructured features can better simulate cellular environments by providing greater surface area and reactive sites for initial protein interactions that can mediate osteoblast adhesion. Kim et al. [11] found that an anodic oxide layer which is relatively thicker and more uniform than those formed naturally enhances corrosion resistance and abrasion, thus significantly increasing alkaline phosphatase activity.

Shokuhfar et al. [2] analysed the interaction between osteoblasts and amorphous and crystalline titanium dioxide 
and concluded that the high wettability of their surfaces is due to crystallinity exerting greater influence on cell spreading. A hydrophilic surface also shows higher protein adsorption than a hydrophobic surface, which produces a positive effect on cell growth. Among crystalline phases of $\mathrm{TiO}_{2}$, anatase and rutile are less soluble in physiological fluids than amorphous films, thus forming a more corrosion-resistant passive oxide layer [12].

A crystallization mechanism of anodic films has been proposed by Chen and Zhou [13] by considering that amorphous, anatase, and rutile phases of $\mathrm{TiO}_{2}$ present a structure which is similar to reticular $\mathrm{TiO}_{6}$ octahedral units that can be coupled by sharing their edges (favouring the anatase structure) or their vertices (in the case of rutile). This process is initiated by dehydrating $\left[\mathrm{Ti}(\mathrm{OH})_{6}\right]^{2-}$, which depends on the amount of hydroxyl ions and electrolyte temperature, thus affecting the solubility of $\mathrm{Ti}^{4+}$ ions in water.

Anatase can promote apatite nucleation at a faster growth rate than rutile due to its better lattice match with apatite crystals [14]. A progressive crystallization of $\mathrm{TiO}_{2}$ can be observed as samples are anodised. By altering anodisation parameters such as voltage and electrolyte composition, an anodic film can be formed on the titanium substrate [15-17].

A previous study [18] demonstrated that anodisation by pulsed current plays an important role in modifying implant surfaces, as it enhances cellular response, which leads to increased cellular population, brings benefits regarding medical and dental procedures, and results in a faster and more effective osseointegration process. In this context, the present work aimed to create a more biocompatible surface through anatase formation by pulsed current at different frequencies and room temperature for anodisation processes.

\section{Material and Methods}

Commercially pure titanium (Grade 2$)$ sheets $(10 \times 10 \mathrm{~mm})$ were mechanically abraded by using 400,600 , and 1200 emery papers. Then, the sheets were separated into a couple of groups and submitted to two polishing methods: some of the samples were electropolished by automatic polishing and using an electrolytic etching Buehler Electromet 4, and another portion of samples was polished with an automatic rotating polisher (Allied Met Prep 3) by diamond suspension. The samples were anodised at $0.1 \mathrm{~A} \mathrm{~cm}^{-2}$ pulsed current and maximum voltage of $30 \mathrm{~V}$ by using a digital oscilloscope (MO2061 manufactured by Minipa) and a square wave pulsed rectifier (GI21P-10/30 by General Inverter). Each titanium sample was the working electrode, a copper plate was the counter-electrode, and $2.5 \mathrm{~mol} / \mathrm{L} \mathrm{H}_{3} \mathrm{PO}_{4}$ was used as electrolyte.

The anodisation process occurred in two stages, in which the effect of anodisation at periods of 15,30 , and $60 \mathrm{~min}$, $100 \mathrm{~Hz}$ frequency, and $40 \%$ duty cycle was performed in the first one, while $60 \mathrm{~min}$ of anodisation time was set for each duty cycle at varied frequencies $(10,1$, and $0.33 \mathrm{~Hz})$ in the second one.

Titanium oxide films were identified using a Horiba Scientific T64000 Raman spectrometer through laser radiation beam with excitation wavelength of $514 \mathrm{~nm}$ (10-fold $60 \mathrm{sec}$ exposure to obtain each spectrum). The surface topography of anodised samples was analysed by using scanning electron microscopy (SEM, ZEISS DSM 940). The crystal structure of anodised surfaces was determined by using low-angle X-ray diffraction (D8 Advance, Bruker Co.). Cross-sectional layer thickness was evaluated by using an optical microscope Zeiss Axio Imager Z2m with circular differential interference contrast (C-DIC). Measurements of electrochemical impedance spectroscopy (EIS) were made in a $0.9 \% \mathrm{NaCl}$ solution containing chloride ion concentration which is similar to that found in blood plasma [19]. Electrochemical measurements were made by a PGSTAT302 potentiostat (Eco. Chemie B. V., Utrecht, Netherlands). A thermostatic cell $\left(37^{\circ} \mathrm{C} \pm 1^{\circ} \mathrm{C}\right)$ was used with three electrodes, in which each anodised sample was the working electrode. A Pt wire was used as counter-electrode and all potentials were measured against a saturated $\mathrm{Ag} / \mathrm{AgCl} / \mathrm{KCl}_{\text {sat }}$ electrode. EIS spectra were recorded at open circuit potential (OCP) by applying a $10 \mathrm{mV}$ sinusoidal potential at frequencies ranging from $100 \mathrm{kHz}$ to $10 \mathrm{mHz}$. Data fitting was carried out by FRA software (4.9 Frequency Response Analyser, Eco. Chemie B. V., Utrecht, Netherlands).

\section{Results and Discussion}

Figure 1 shows instantaneous pulsed current values (frequency pulses at $100 \mathrm{~Hz}$ ) after 30 and 55 minutes of anodisation time, which enables a comparison of electropolished (Figure 1(a)) and nonelectropolished (Figure 1(b)) surfaces. All other experimental conditions for obtaining such values were identical in both cases. According to these graphs, a square wave was only observed while the polished surfaces were being anodised. An ideal square wave alternates regularly between two levels, maximum and minimum. For such a process, three parameters should be adjusted: pulsed current duration $\left(t_{\mathrm{on}}\right)$, time between current pulses $\left(t_{\mathrm{off}}\right)$, and current pulse magnitude. The relation between $t_{\text {on }}$ and $t_{\text {off }}$ determines duty cycle $(\mathrm{dc})$ and frequency $(f)$ of the process, which are defined as $\mathrm{dc}=t_{\text {on }} /\left(t_{\text {on }}+t_{\text {off }}\right)$ and $f=1 /\left(t_{\text {on }}+t_{\text {off }}\right)$ [20].

Raman spectra (Figures 2(a) and 2(b)) showed weak bands that became stronger as a result of increased anodisation time as regards electropolished substrates. The lack of strong and well-defined peaks indicates that films are predominantly amorphous or nanocrystalline, but it can also be due to the fact that the film is very thin $[21,22]$. After 60 min of anodisation, an intense peak at $147 \mathrm{~cm}^{-1}$ and three well-defined bands with respect to the polished sample were observed, which are consistent with literature on the anatase phase [23]. Greater crystallinity is a result of longer anodisation time, which is in agreement with observations made by Xing et al. [24]. XRD spectra (Figure 3) showed that the anodic film on a polished titanium surface consisted mainly of anatase. A higher intensity peak that is close to 25 degrees is another indicative of anatase.

Figure 4 describes SEM images of anodic titanium oxide films formed at $30 \mathrm{~V}$ and different current pulse frequencies 


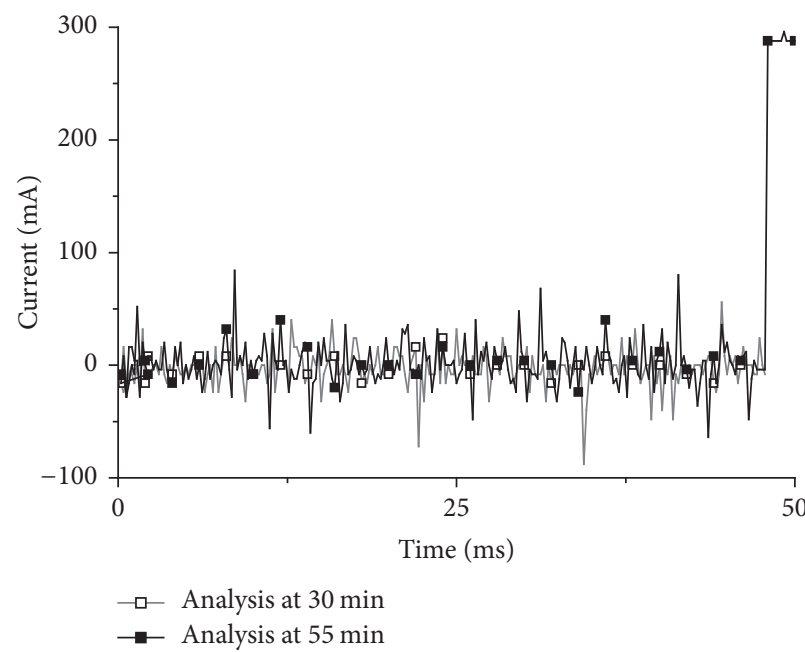

(a)

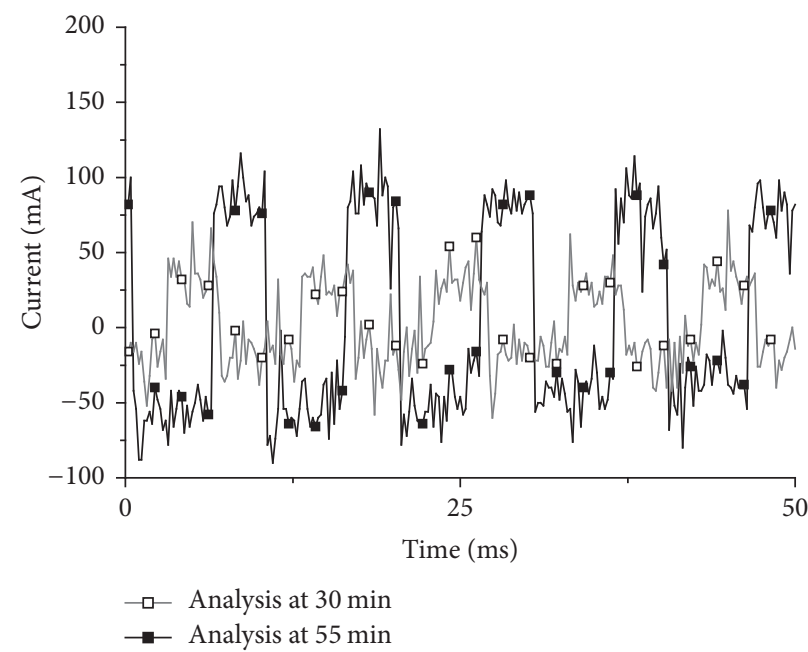

(b)

FIGURE 1: Oscilloscope data for pulsed current anodisation of 60 min on titanium surfaces: (a) electropolished and (b) nonelectropolished surfaces.

of polished substrates. The film morphology has not significantly changed by decreasing frequency from 100 to $0.33 \mathrm{~Hz}$, but an increase in grain size, number, and pore size was observed at lower frequencies. An increase in average size of crystalline grains can be similarly explained by the crystal growth in a precipitation process from a supersaturated solution. Precipitation consists of two distinct events: nucleation, or the initial formation of smaller stable crystals, and their subsequent growth. Larger crystals are formed when crystal growth rate exceeds nucleation rate.

A similar structure, such as a flower-like or nodulelike structure, has been suggested in literature [24], which is composed mainly of crystalline $\mathrm{TiO}_{2}$ grains and can be associated with the film dielectric breakdown features. Light microscopy in Figure 5 shows a cross-sectional anodic layer on one of the polished samples, which has revealed that the oxide film is about $20 \mu \mathrm{m}$ thick and does not seem to have discontinuities on the titanium substrate.

The mechanism for amorphous oxide formation, as well as its transition to crystalline oxide, has been reported by several authors $[15,17,25-28]$. The formation of $\mathrm{TiO}_{2}$ via anodic oxidation starts from metal oxidation and dissociation of water at the metal/electrolyte interface. The applied electric field directs the $\mathrm{Ti}^{4+}$ ions towards the electrolyte, while $\mathrm{O}^{2-}$ and $\mathrm{OH}^{-}$ions are towards the anode. Pores are formed by the migration and oxidation of $\mathrm{O}^{2-}$ ions along the $\mathrm{TiO}_{2}$ matrix, which is accumulated in the form of $\mathrm{O}_{2}$ bubbles. The anatase phase is known to have better electrical conductivity than amorphous $\mathrm{TiO}_{2}$, thus favouring charge transfer processes during anodisation, whereas the cathode reaction reduces the number of $\mathrm{H}^{+}$ions.

Figure 6 illustrates EIS spectra in Nyquist format obtained for polished titanium after anodisation at different current pulse frequencies, through which distorted capacitive semicircles can be observed in Figure 6(a). One disadvantage of displaying experimental data through complex plane plots is the fact that the impedance dependence on the applied signal frequency is not directly shown. Therefore, Bode plots are shown in Figures 6(b) and 6(c). The modulus and phase shift dependence on the frequency of each experimental condition are very similar, which indicates that the morphologies of anodic films are similar as well. An overlap of graphs shows differences in diameters of capacitive arcs with small variations in the impedance modulus and phase angle at low frequencies, which may indicate that the morphology of films does not change, even by varying the current pulse frequencies during anodisation. These differences are due to the number and distribution of crystalline nuclei on anodised surfaces.

An interpretation of these graphs was obtained by a fitting procedure with equivalent electrical circuit software, and fitted data are shown overlaid on each respective curve as solid lines.

Equivalent circuit was initially based on a two-layer structure model, Figure 7(a), as proposed by Williamson et al. [12] and Roach et al. [14], in which $R_{\Omega}$ is the uncompensated ohmic resistance, otherwise known as solution resistance. The parallel association $\left(Q_{1}\right.$ and $\left.R_{1}\right)$ represents an outer porous layer and the electrical elements $\left(Q_{2}\right.$ and $R_{2}$ ) symbolize an inner barrier layer which is bound to a Warburg diffusion element near the titanium substrate. Since real surfaces of solid electrodes are always inhomogeneous, a representation of the electrochemical behaviour to investigate protecting properties of films on metals using simple equivalent electrical circuits is not viable. Possible defects and characteristics of films that are detectable by using EIS may often be ascribed to an imperfect cell geometry, which results in a nonuniform current distribution, since the corrosion process takes place on defects in a nonhomogeneous surface. $Q_{1}$ and $Q_{2}$ are the constant phase elements used 

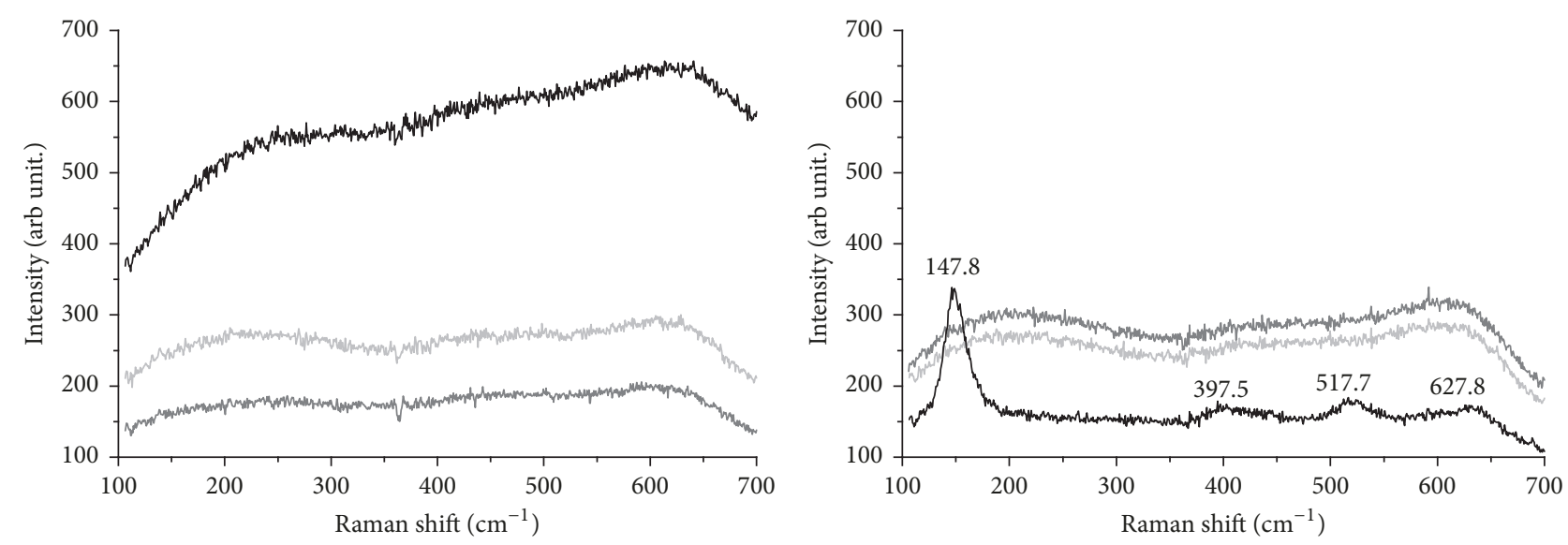
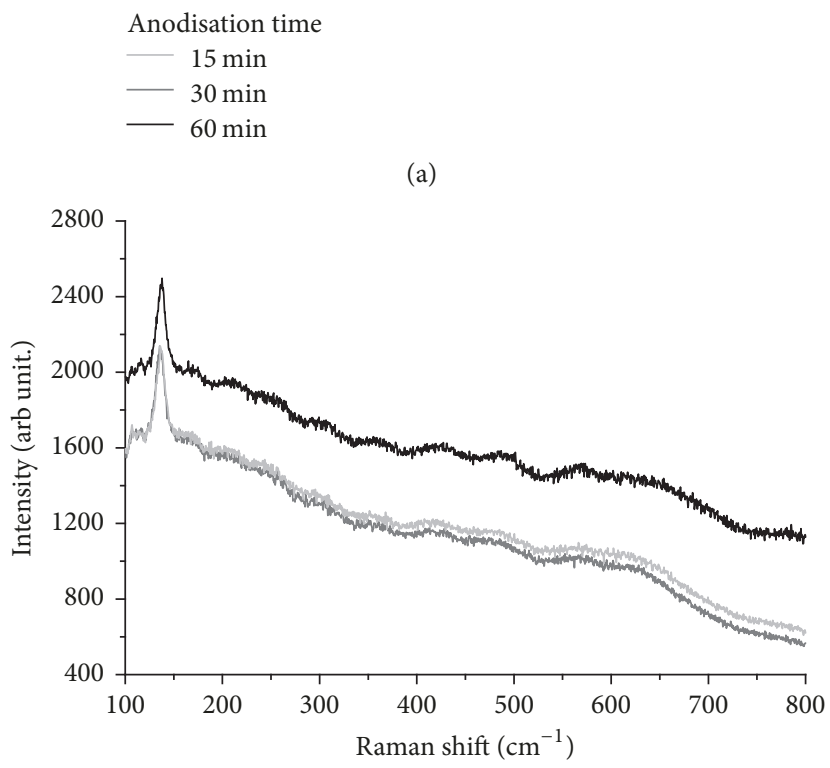

Frequencies of current pulses

$-0.33 \mathrm{~Hz}$

$-1 \mathrm{~Hz}$

$-10 \mathrm{~Hz}$

(c)
Anodisation time
$15 \mathrm{~min}$
- $30 \mathrm{~min}$
- $60 \mathrm{~min}$

(b)

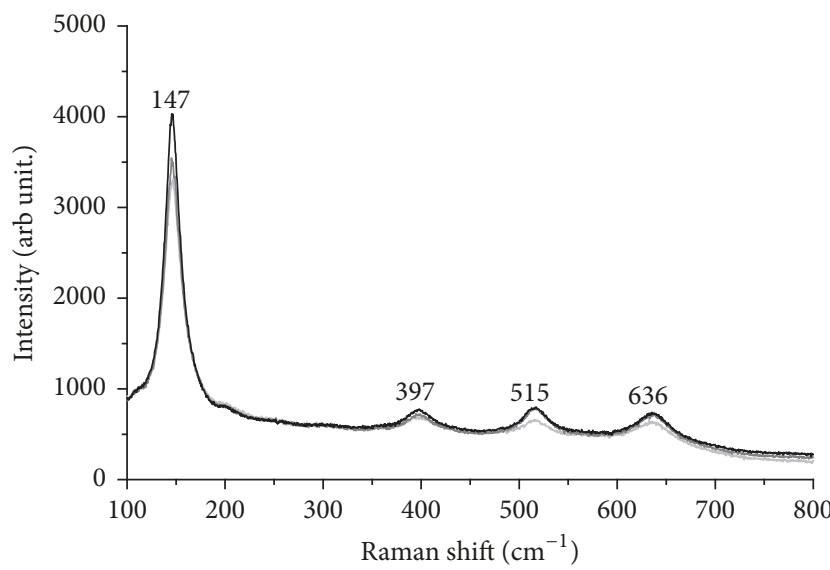

Frequencies of current pulses

$0.33 \mathrm{~Hz}$

$1 \mathrm{~Hz}$

$-10 \mathrm{~Hz}$

FIgURE 2: Raman spectra of formed films on electropolished (a, c) and nonelectropolished (b, d) titanium surfaces.

for fitting data instead of capacitance $C$ and are related to nonuniform current distributions due to surface roughness or inhomogeneity. The inclusion of a constant phase element $(Q)$ in the equivalent circuit provides parameter $n$ that corresponds to either spectral degree of distortion or surface roughness.

Tables 1 and 2 show the parameters fitted for experimental results using equivalent circuit models depicted in Figures $7(\mathrm{a})$ and $7(\mathrm{~b})$. Low $\chi^{2}$ values, in the order of $10^{-3}$, that is, the sum of quadratic deviations between experimental and calculated data, were observed for both circuit models, suggesting that both of them may be suitable for explaining the impedance spectra.
TABLE 1: Impedance parameters obtained using the circuit model of Figure 7(a).

\begin{tabular}{lcccccccc}
\hline $\begin{array}{l}\text { Frequency } \\
\text { of current } \\
\text { pulses }(\mathrm{Hz})\end{array}$ & $\begin{array}{c}R_{\Omega} \\
(\Omega)\end{array}$ & $\begin{array}{c}\mathrm{Q}_{1} \\
\left(\mu \mathrm{S} s^{n}\right)\end{array}$ & $n_{1}$ & $\begin{array}{c}R_{1} \\
(k \Omega)\end{array}$ & $\begin{array}{c}\mathrm{Q}_{2} \\
\left(\mu \mathrm{S} s^{n}\right)\end{array}$ & $\begin{array}{c}n_{2} \\
(k \Omega)\end{array}$ & $\begin{array}{c}R_{2} \\
\left(\mu \mathrm{S} s^{1 / 2}\right)\end{array}$ \\
\hline 10 & 42.5 & 20.8 & 0.91 & 4.90 & 157 & 0.73 & 4.90 & 1730 \\
1 & 36.6 & 17.1 & 0.93 & 17.3 & 227 & 0.70 & 19.8 & 683 \\
0.33 & 32.9 & 25.5 & 0.93 & 107 & 86.5 & 0.62 & 103 & 621 \\
\hline
\end{tabular}

Unlike Williamson et al. [12] and Roach et al. [14], the inner and outer layer resistances herein $\left(R_{2}\right.$ and $R_{1}$, respectively) were very similar (Table 1 ). This result indicates 

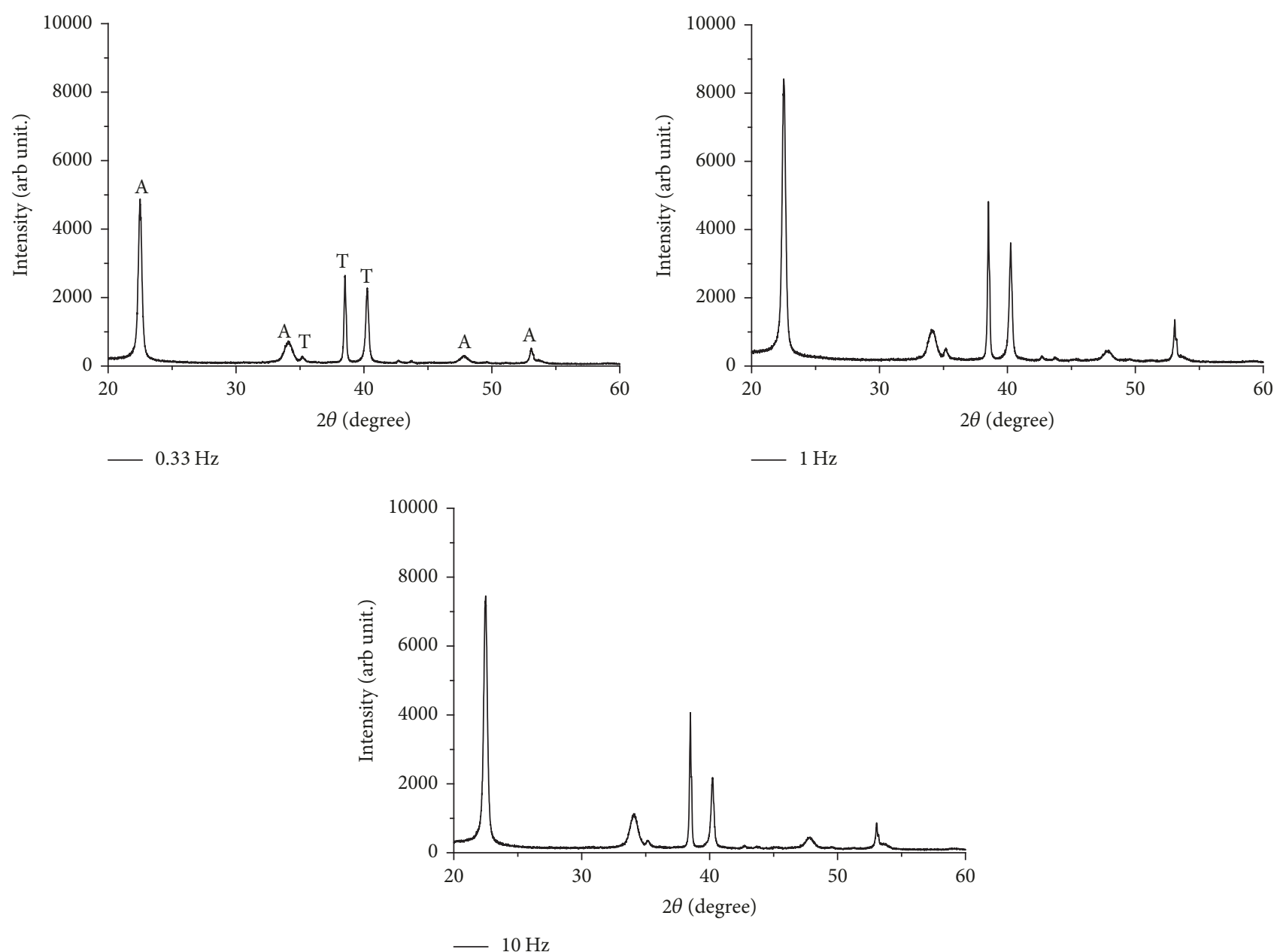

FIGURE 3: XRD spectra of nonelectropolished titanium surfaces after anodisation at different pulsed current frequencies (A: anatase, T: titanium).

TABLE 2: Impedance parameters obtained using the circuit model of Figure 7(b).

\begin{tabular}{lccccc}
\hline $\begin{array}{l}\text { Frequency of } \\
\text { current pulses } \\
(\mathrm{Hz})\end{array}$ & $R_{\Omega}(\Omega)$ & $\mathrm{Q}\left(\mu \mathrm{S} s^{n}\right)$ & $n$ & $R_{p}(k \Omega)$ & $\left.W(\mathrm{mS} \mathrm{s})^{1 / 2}\right)$ \\
\hline 10 & 43.4 & 28.6 & 0.84 & 7.93 & 1.07 \\
1 & 40.4 & 21.8 & 0.84 & 3.27 & 23.7 \\
0.33 & 37.3 & 31.6 & 0.82 & 4.97 & 10.5 \\
\hline
\end{tabular}

that there is no difference in the degree of compactness along the layer thickness. Thus, a simpler equivalent electric circuit model was chosen, given that the film should be composed of a single layer, in which polarization resistance $\left(R_{p}\right)$ can be considered as film resistance. $R_{p}$ values (Table 2 ) were more coherent with experimental data in Figure 6 for the present model. Thereby, the anodic film formed at $10 \mathrm{~Hz}$ current pulse is the most resistant to corrosion.
Another apparently contradictory result regarding the choice of the most complex equivalent circuit was the fact that $Q_{1}$ values are lower than those obtained for $Q_{2}$ (Table 1). In addition, their respective $n_{1}$ values were greater than 0.9 (typical of a homogeneous and compact surface) while those found for $n_{2}$ were around 0.7 (normally designed to represent a rough surface), once it is expected that $Q_{1}>Q_{2}$ by the fact that $Q_{1}$ refers to the most porous layer.

In both circuit models, the best data fitting was obtained after inserting a Warburg diffusion element, thence indicating that a diffusion process occurs through the oxide layer. As stated by Roach et al. [14], a nanostructured pore network seems to interconnect the outer layer with the inner layer; thus the electrolyte reaches the titanium substrate.

\section{Conclusions}

This work aimed to study anatase formation on titanium by using low-voltage current pulses in an anodisation process at room temperature. It was found that the anatase film was only formed on nonelectropolished titanium surfaces. 


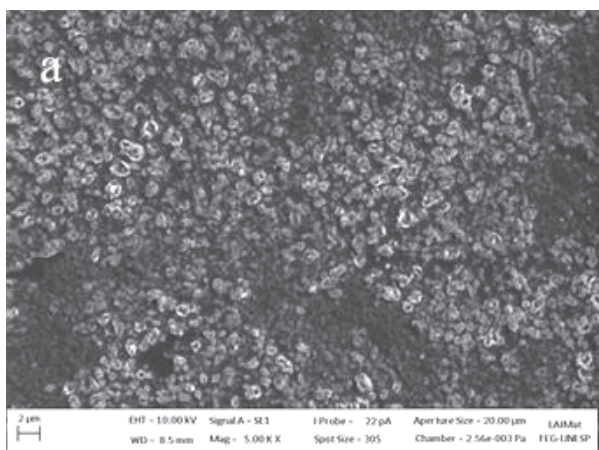

(a)

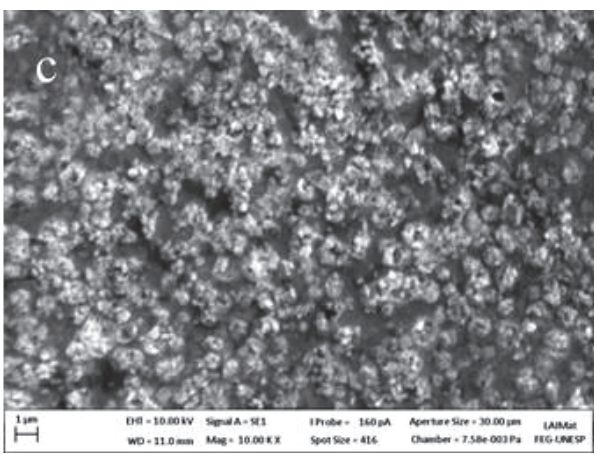

(c)

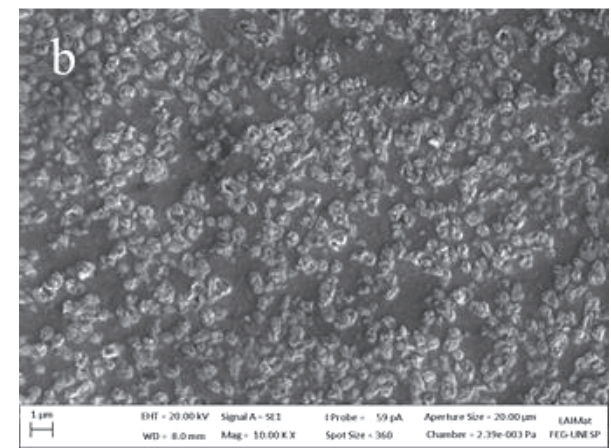

(b)

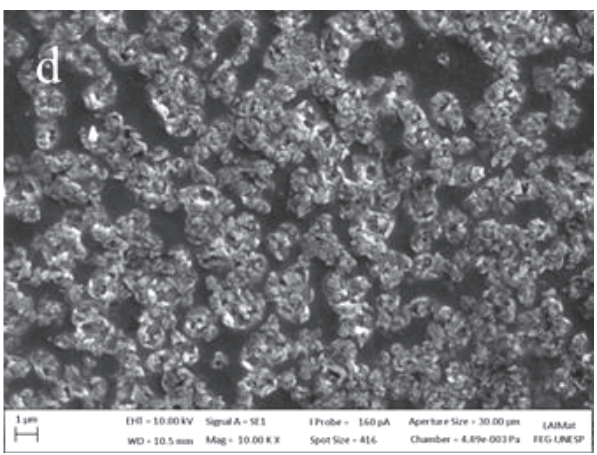

(d)

FIGURE 4: SEM images of nonelectropolished titanium surfaces after anodisation at different pulsed current frequencies: (a) $100 \mathrm{~Hz}$; (b) $10 \mathrm{~Hz}$; (c) $1 \mathrm{~Hz}$; and (d) $0.33 \mathrm{~Hz}$.

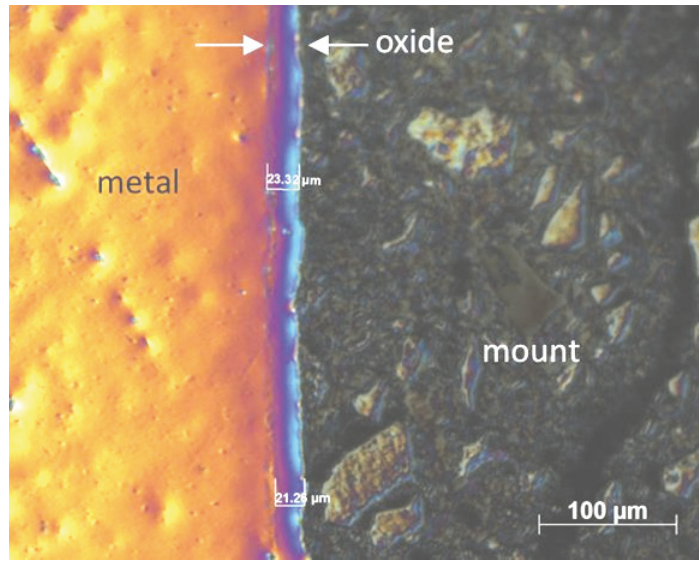

FIGURE 5: Cross-sectional image of the nonelectropolished and anodised titanium sample to evaluate oxide layer thickness.

Anatase phase proportion seems to be greater with increased anodisation time, and the smallest crystals were obtained at the highest current pulse frequencies. An amorphous or nanocrystalline film was formed on the electropolished titanium surface in the same experimental conditions as those of nonelectropolished titanium surfaces. For anodic film thicknesses of about $20 \mu \mathrm{m}$, EIS results revealed that there is no difference in the degree of compactness along the oxide film thickness, hence suggesting single layer formation.

\section{Conflicts of Interest}

The authors declare that they have no conflicts of interest.

\section{Acknowledgments}

This work was supported by FAPESP. Thanks are due to the Multiuser Laboratory of Advanced Optical Spectroscopy, 


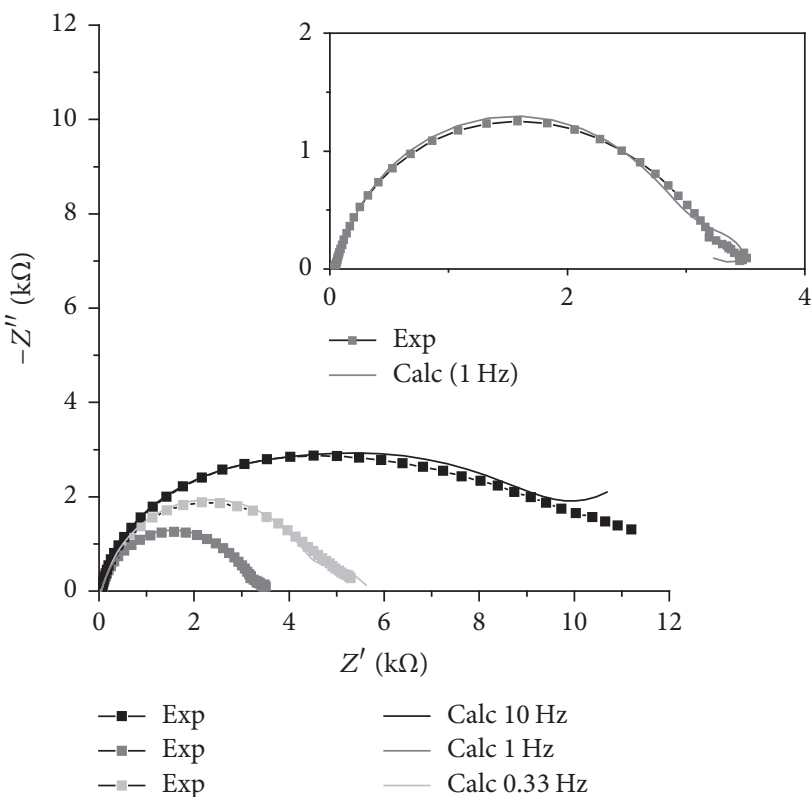

(a)

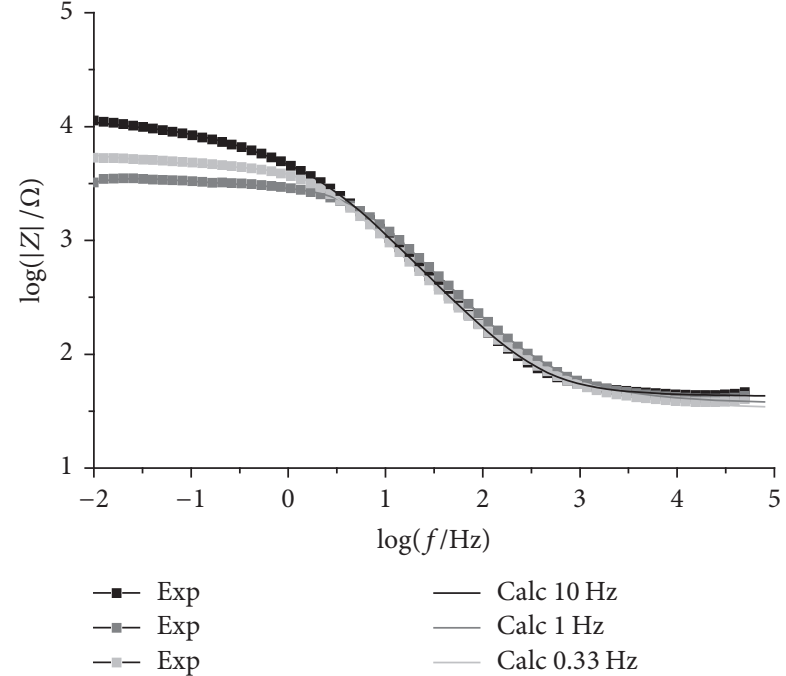

(b)

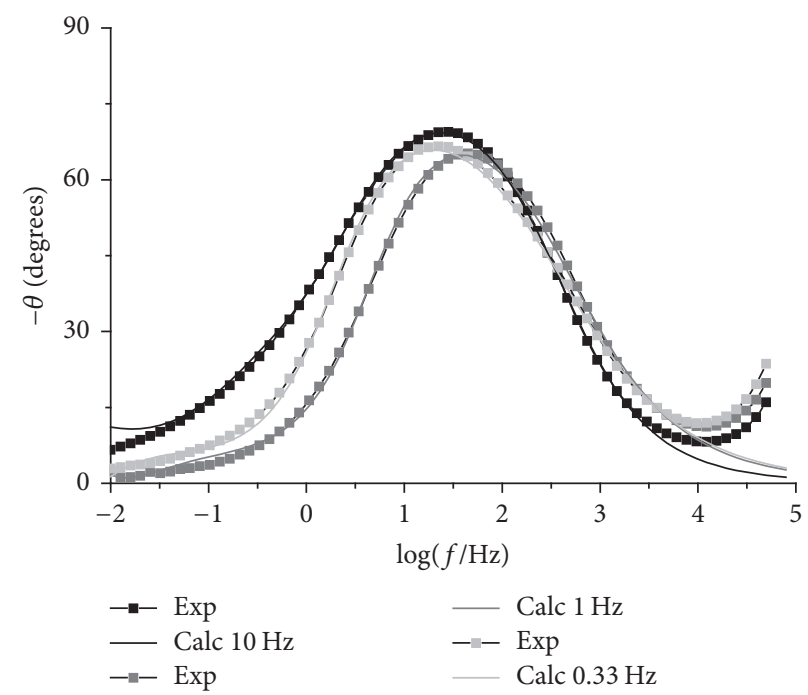

(c)

FIGURE 6: EIS spectra obtained in Nyquist format for nonelectropolished titanium surfaces after anodisation at different pulsed current frequencies in $0.9 \% \mathrm{NaCl}$ solution. Calculated (Calc) values are represented by a solid line, which were obtained by data fitting through the equivalent circuit model of Figure 7(a).

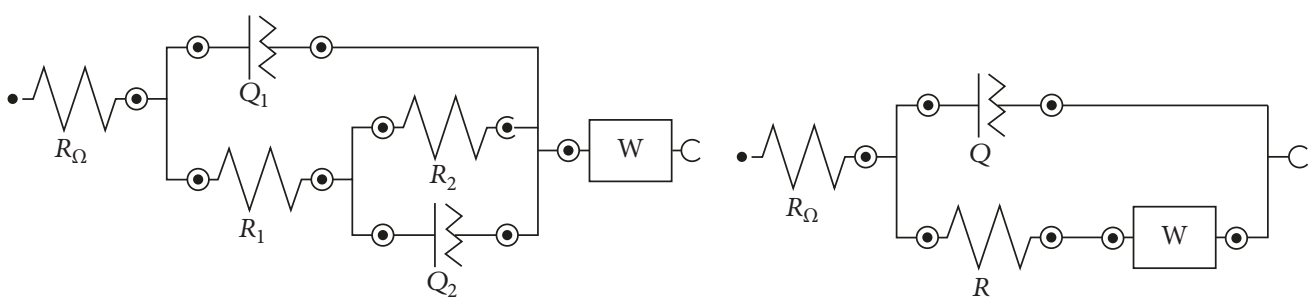

(a)

(b)

FIGURE 7: Equivalent electrical circuits proposed for fitting impedance spectra: (a) one based on a two-layer structure model; (b) a simpler circuit model. 
Unicamp, and to Dr. L. R. O. Hein for SEM images and DRX spectra.

\section{References}

[1] J. Zuo, X. Huang, X. Zhong et al., "A comparative study of the influence of three pure titanium plates with different micro- and nanotopographic surfaces on preosteoblast behaviors," Journal of Biomedical Materials Research Part A, vol. 101, no. 11, pp. 3278-3284, 2013.

[2] T. Shokuhfar, A. Hamlekhan, J.-Y. Chang, C. K. Choi, C. Sukotjo, and C. Friedrich, "Biophysical evaluation of cells on nanotubular surfaces: the effects of atomic ordering and chemistry," International Journal of Nanomedicine, vol. 9, pp. 3737-3748, 2014.

[3] G. Polizzi, F. Gualini, and B. Friberg, "A two-center retrospective analysis of long-term clinical and radiologic data of tiunite and turned implants placed in the same mouth," International Journal of Prosthodontics, vol. 26, no. 4, pp. 350-358, 2013.

[4] E. Rieger, A. Dupret-Bories, L. Salou et al., "Controlled implant/soft tissue interaction by nanoscale surface modifications of 3D porous titanium implants," Nanoscale, vol. 7, no. 21, pp. 9908-9918, 2015.

[5] D. L. Torres, M. C. Pereira, J. W. J. Silva, E. N. Codaro, and H. A. Acciari, "Effect of phosphoric acid concentration and anodizing time on the properties of anodic films on titanium," Journal of Engineering Science and Technology, vol. 10, no. 7, pp. 841-848, 2015.

[6] S. A. Yavari, B. S. Necula, L. E. Fratila-Apachitei, J. Duszczyk, and I. Apachitei, "Biofunctional surfaces by plasma electrolytic oxidation on titanium biomedical alloys," Surface Engineering, vol. 32, no. 6, pp. 411-417, 2016.

[7] G. Doroudian, M. W. Curtis, A. Gang, and B. Russell, "Cyclic strain dominates over microtopography in regulating cytoskeletal and focal adhesion remodeling of human mesenchymal stem cells," Biochemical and Biophysical Research Communications, vol. 430, no. 3, pp. 1040-1046, 2013.

[8] M.-H. Kim, K. Park, K.-H. Choi et al., "Cell adhesion and in vivo osseointegration of sandblasted/acid etched/anodized dental implants," International Journal of Molecular Sciences, vol. 16, no. 5, pp. 10324-10336, 2015.

[9] R. S. Williamson, J. Disegi, J. A. Griggs, and M. D. Roach, "Nanopore formation on the surface oxide of commercially pure titanium grade 4 using a pulsed anodization method in sulfuric acid," Journal of Materials Science: Materials in Medicine, vol. 24, no. 10, pp. 2327-2335, 2013.

[10] C. Yao, E. B. Slamovich, and T. J. Webster, "Enhanced osteoblast functions on anodized titanium with nanotube-like structures," Journal of Biomedical Materials Research Part A, vol. 85, no. 1, pp. 157-166, 2008.

[11] K. Kim, B.-A. Lee, X.-H. Piao, H.-J. Chung, and Y.-J. Kim, "Surface characteristics and bioactivity of an anodized titanium surface," Journal of Periodontal \& Implant Science, vol. 43, no. 4, pp. 198-205, 2013.

[12] R. S. Williamson, J. Disegi, A. V. Janorkar, J. A. Griggs, and M. D. Roach, "Effect of duty cycle on the crystallinity, pore size, surface roughness and corrosion resistance of the anodized surface on titanium," Surface and Coatings Technology, vol. 277, pp. 278-288, 2015.

[13] Z. Chen and K. Zhou, "Surface morphology, phase structure and property evolution of anodized titanium during water vapor exposure," Surface and Coatings Technology, vol. 263, pp. 61-65, 2015.

[14] M. D. Roach, R. S. Williamson, I. P. Blakely, and L. M. Didier, "Tuning anatase and rutile phase ratios and nanoscale surface features by anodization processing onto titanium substrate surfaces," Materials Science and Engineering C: Materials for Biological Applications, vol. 58, pp. 213-223, 2016.

[15] M. Fan and F. La Mantia, "Effect of surface topography on the anodization of titanium," Electrochemistry Communications, vol. 37, pp. 91-95, 2013.

[16] A. Nazari and S. Saedodin, "Porous anodic alumina coating for optimisation of pool-boiling performance," Surface Engineering, vol. 844, pp. 1-6, 2016.

[17] C. Fu, H. Liang, M. Yu, J. Liu, and S. Li, "Effect of tartaric acid concentration on the anodic behaviour of titanium alloy," International Journal of Electrochemical Science, vol. 10, no. 4, pp. 3431-3441, 2015.

[18] L. M. R. Vasconcellos, M. F. L. Villaça-Carvalho, R. F. Prado et al., "A study about cell activity on anodized Ti-6Al-4V by means of pulsed current," Journal of Engineering Science and Technology, vol. 12, no. 5, pp. 1240-1252, 2017.

[19] T. Kokubo and H. Takadama, "How useful is SBF in predicting in vivo bone bioactivity?" Biomaterials, vol. 27, no. 15, pp. 29072915, 2006.

[20] N. N. Regone, C. M. A. Freire, and M. Ballester, "Al-based anodic oxide films structure observation using field emission gun scanning electron microscopy," Journal of Materials Processing Technology, vol. 172, no. 1, pp. 146-151, 2006.

[21] I. A. Alhomoudi and G. Newaz, "Residual stresses and Raman shift relation in anatase $\mathrm{TiO}_{2}$ thin film," Thin Solid Films, vol. 517, no. 15, pp. 4372-4378, 2009.

[22] H.-Y. Si, Z.-H. Sun, X. Kang, W.-W. Zi, and H.-L. Zhang, "Voltage-dependent morphology, wettability and photocurrent response of anodic porous titanium dioxide films," Microporous and Mesoporous Materials, vol. 119, no. 1-3, pp. 75-81, 2009.

[23] V. C. Nettikaden, H. Liu, P. Skeldon, and G. E. Thompson, "Porous anodic film formation on Al-Ti alloys in sulphuric acid," Corrosion Science, vol. 57, pp. 49-55, 2012.

[24] J. Xing, Z. Xia, J. Hu, Y. Zhang, and L. Zhong, “Time dependence of growth and crystallization of anodic titanium oxide films in potentiostatic mode," Corrosion Science, vol. 75, pp. 212219, 2013.

[25] D. Regonini, C. R. Bowen, A. Jaroenworaluck, and R. Stevens, "A review of growth mechanism, structure and crystallinity of anodized $\mathrm{TiO}_{2}$ nanotubes," Materials Science and Engineering: R: Reports, vol. 74, no. 12, pp. 377-406, 2013.

[26] J. L. Rosa, A. Robin, R. Z. Nakazato, M. B. Ribeiro, M. P. Piassa, and M. B. Silva, "Formation of titania nanotube arrays by anodisation: DOE approach," Surface Engineering, vol. 30, no. 2, pp. 115-122, 2014.

[27] L. Giorgi, E. Salernitano, T. Dikonimos Makris et al., "Titania nanotubes self-assembled by electrochemical anodization: Semiconducting and electrochemical properties," Thin Solid Films, vol. 601, pp. 28-34, 2016.

[28] C. Jaeggi, M. Parlinska-Wojtan, and P. Kern, "Correlation of electrolyte-derived inclusions to crystallization in the early stage of anodic oxide film growth on titanium," Thin Solid Films, vol. 520, no. 6, pp. 1804-1808, 2012. 


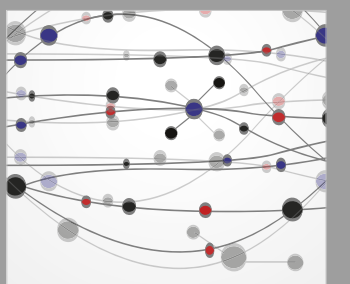

The Scientific World Journal
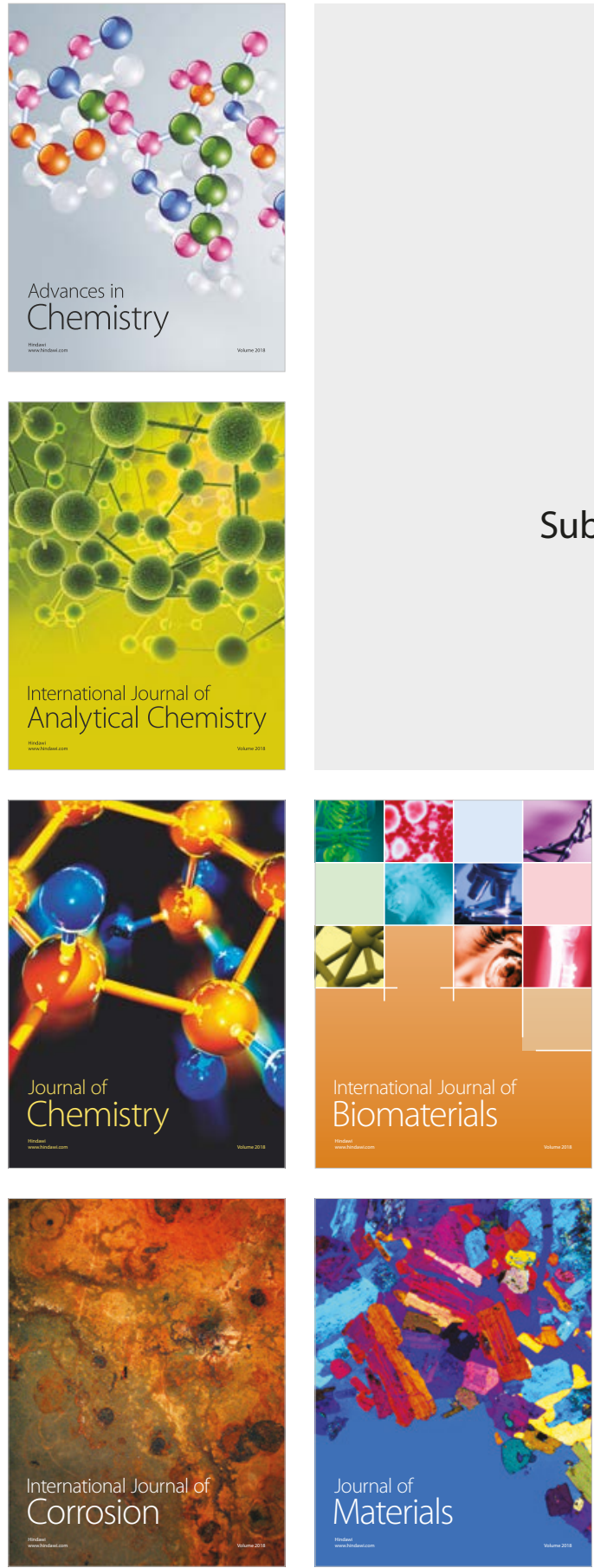

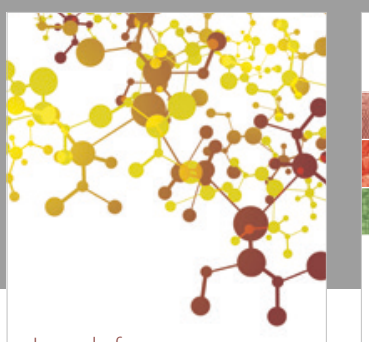

Journal of

Applied Chemistry
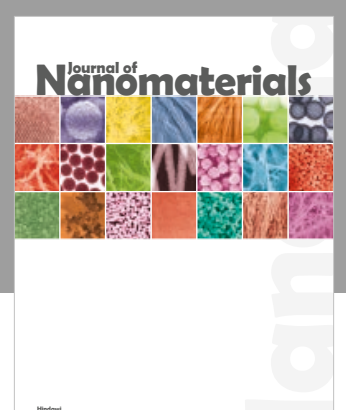

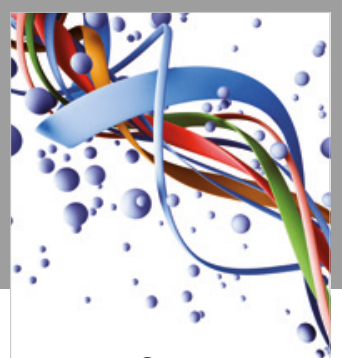

Scientifica

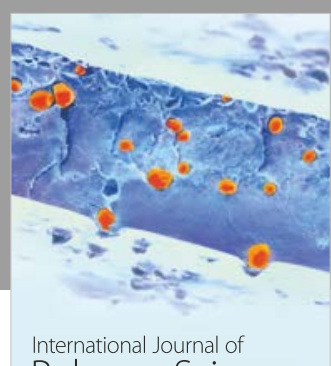

Polymer Science

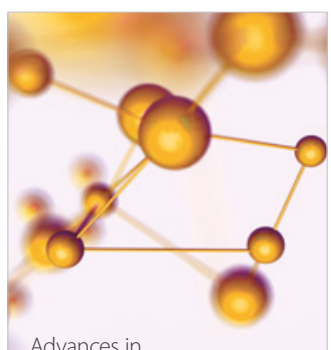

Physical Chemistry
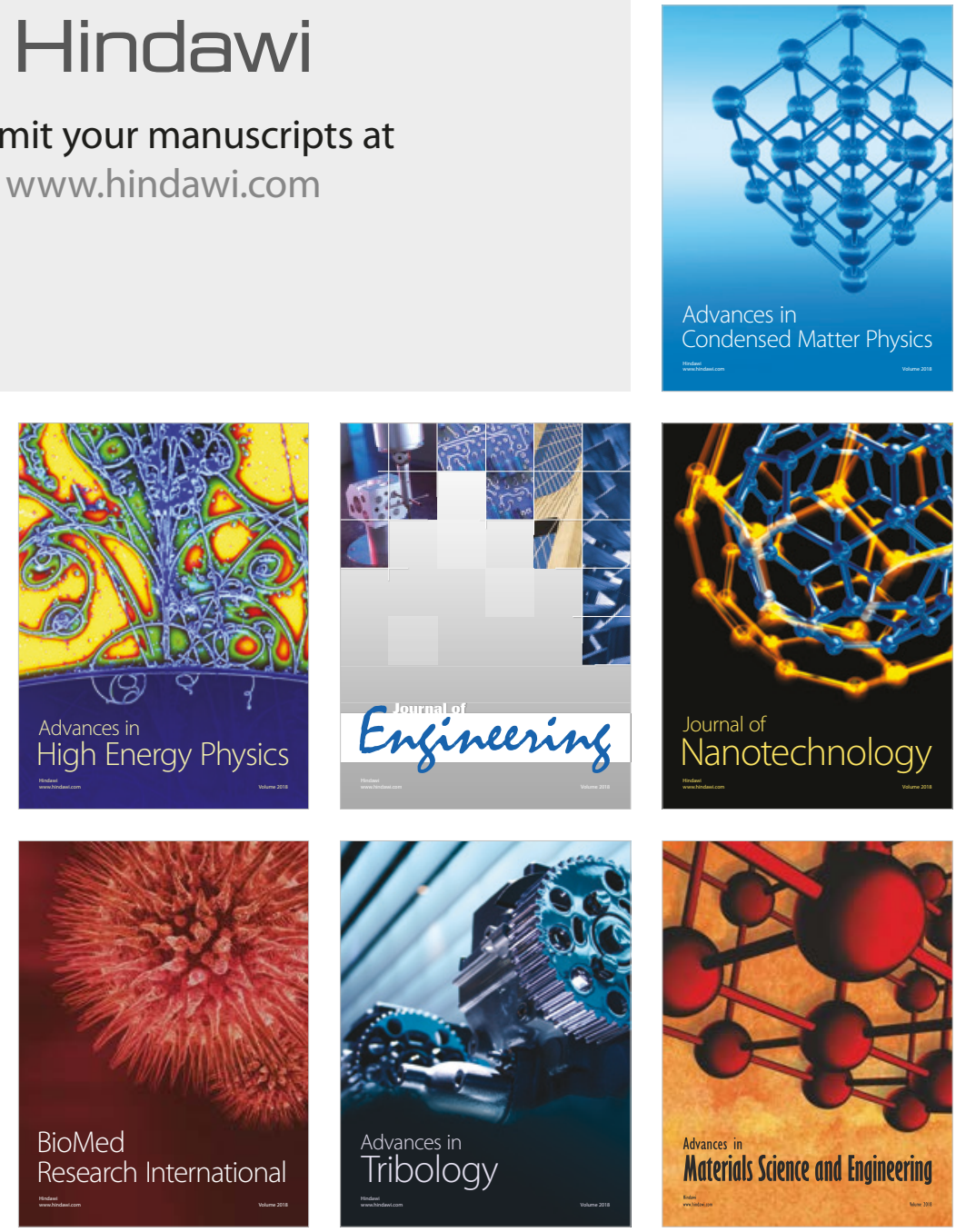